\title{
SERBIE
}

\section{LE BRANCARD DE L'ARMÉE SERBE}

M. le colonel $\mathrm{Dr}$ Borisavlievitch-Petzutch est l'inventeur d'un excellent brancard, simple, solide et léger, qui a été adopté dans l'armée serbe. Voici la description qu'en donne l'auteur dans une courte notice qu'il nous en a fait tenir récemment :

Le brancard se compose de deux barres rondes, en bois, longues de 2 in 45 . Sur les barres est tendue la toile, avec l'oreiller, sur une longueur de $1^{\mathrm{m}} 75$. La longueur du brancard est de $0^{\mathrm{m}} 75$. La toile enveloppe les barres et est cousue en dessous.

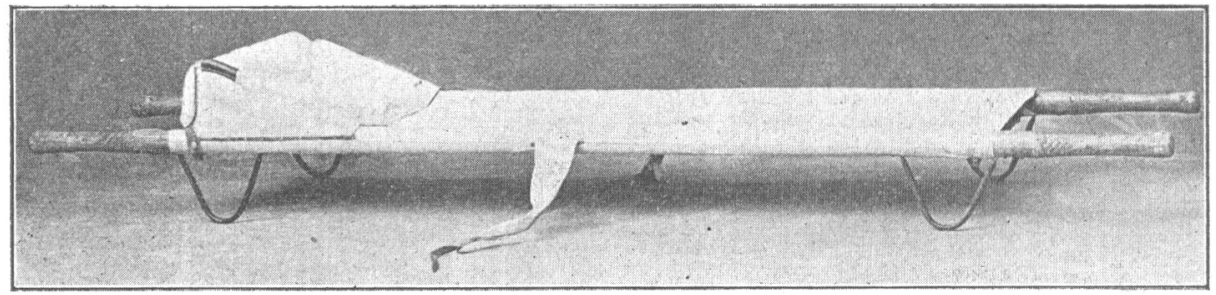

L'oreiller est posé sur la toile formant avec elle un angle de 25 degrés; il repose sur une traverse ronde et tordue (creuse). Au-dessous de l'oreiller se trouve un espace vide dans lequel peuvent se réduire différents objets nécessaires au blessé ou bien des articles de pansement.

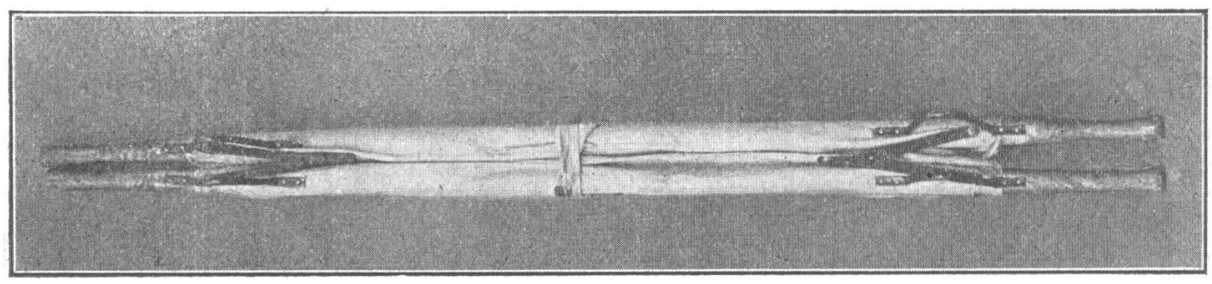

Le brancard repose sur des pieds en fer rond creux, hauts de ( $\mathrm{m}$ 14. Il se plie let se déplie à l'aide de traverses plates en fer, fixées en dessous, entre les pieds, et munies au milieu d'une 


\section{9}

charnière. Par-dessus et au milieu du brancard est fixé, sur chaque barre, un ruban large en toile, muni à son extrémité d'une lanière en cuir avec boucle, pour la fixation du blessé.

Le brancard pèse 8 kilos et demi, il se plie et se déplie instantanément et peut servir de lit dans les ambulances de campagne. Il ne coute que 11 francs.

Dr F.

\section{SUEDE}

PRÉSIDENCE DE LA SOCIÉTÉ SUÉDOISE

Nous avons recu du Comité de Stockholm la communication suivante :

Stockholm, le 15 juillet 1903.

Au Comité international de lä Croix-Rouge,

Genève.

Suivant l'ordre du Comité central suédois, j'ai l'honneur de vous faire part de la perte douleureuse que la Société suédoise de la Croix-Rouge vient d'éprouver en la personne de son président, M. le général comte Hamilton, décédé le 1er mai dernier.

En mème temps, je m'empresse de vous annoncer que S. A. R. le prince Charles, duc de Vestrogothie, a daigné se charger de la présidence de notre société.

Pour le Comité:

A. von Heyne, secretaire. 